\title{
Comparative effects of olive oil-based and soyabean oil-based emulsions on infection rate and leucocyte count in critically ill patients receiving parenteral nutrition
}

\author{
Javier Mateu-de Antonio $^{1 *}$, Santiago Grau ${ }^{1}$, Sonia Luque ${ }^{1}$, Mónica Marín-Casino ${ }^{1}$, Inmaculada Albert ${ }^{2}$ and \\ Esther Ribes ${ }^{1}$ \\ ${ }^{1}$ Pharmacy Department and ${ }^{2}$ Intensive Care Unit, Hospital del Mar, Passeig Marítim, 25-29, 08003 Barcelona, Spain
}

(Received 23 October 2006 - Revised 16 July 2007 - Accepted 8 August 2007)

Soyabean oil-based emulsions high in linoleic acid used in parenteral nutrition (PN) could interfere with immune function and may increase the risk of septic complications. Olive oil-based emulsions, high in oleic acid, could have fewer immune effects. We compared the effects of a soyabean oil-based emulsion $v$. an olive oil-based emulsion on infection rate, appearance of new infection episodes, leucocyte count (peak and evolution), acute-phase proteins, and major health outcomes in intensive care unit (ICU) adult patients receiving PN. The study was designed as an observational, retrospective, single-centre, cohort study in a general ICU. Patients in the SOYA cohort $(n$ 16) received a soyabean oil-based emulsion and patients in the OLIVE cohort ( $n$ 23), an olive oil-based emulsion. Both cohorts had similar basal characteristics and received a similar energy load. The SOYA cohort received an oleic acid:linoleic acid ratio of 0.43 and the OLIVE cohort $2.99(P<0.001)$. No differences were observed in infection rate and appearance, acute-phase proteins, and major health outcomes. At the end of PN, blood leucocyte count decreased by $3.25 \times 10^{9}$ cells $/ 1$ in the SOYA cohort and increased by $4.51 \times 10^{9}$ cells/l in the OLIVE cohort from baseline values $(P=0.036)$. Peak leucocyte count presented a trend for a higher value in the OLIVE cohort $v$. the SOYA cohort $\left(18.86 v .15 .28 \times 10^{9}\right.$ cells/l; $\left.P=0.078\right)$. The use of an olive oil-based emulsion in PN had no effect on infection, acute-phase proteins, major health outcomes, and presented higher leucocyte count at the end of PN and a trend to higher peak leucocyte count when compared with soyabean oil-based emulsion in ICU patients.

Parenteral nutrition: Intravenous fat emulsion: Infection: Leucocyte count

Lipid emulsions are used in parenteral nutrition $(\mathrm{PN})$ as a source of energy and of essential fatty acids. Lipids also act as the main component of cell membranes, precursors of eicosanoids, metabolic regulators and immune response modulators $^{1,2}$. Their use in $\mathrm{PN}$ has been associated with a higher complication rate compared with PN without a lipid emul$\operatorname{sion}^{3,4}$. However, intravenous lipid emulsions are not contraindicated in current PN recommendations and now are considered standard practice ${ }^{1,5,6}$. The first marketed emulsions were soyabean oil-based emulsions and they are still widely used. These emulsions have a high content of linoleic acid, the main fatty acid of the n-6 PUFA family. This family is believed to interfere with immune function through several mechanisms, such by being precursors of pro-inflammatory eicosanoids, inhibitors of lymphocyte and macrophage functions, and impairing reticuloendothelial functions ${ }^{1,2,7}$. Recently, a soyabean oil-based emulsion given as a single dose of $500 \mathrm{ml}$ has been shown to decrease human lymphocyte proliferation and promote lymphocyte and neutrophil death ${ }^{8}$. Alterations in the phospholipid fatty acid profile and eicosanoid synthesis have also been seen with lower intakes of soyabean oil-based emulsion in stressed patients ${ }^{9-11}$. Therefore, it has been suggested that these emulsions may increase the patient's susceptibility to septic complications, although this point still remains controversial and further evidence is needed ${ }^{2}$. In recent years, several lipid emulsions have been developed with the aim to decrease the $n-6$ PUFA content from the classical soyabean oil-based emulsions in order to less negatively influence immune function. These emulsions include different amounts of medium-chain TAG, olive oil, and/or fish oil ${ }^{1,2,7,12}$. Specifically, olive oil-based emulsions have been shown to be safe as part of $\mathrm{PN}^{1}$. These emulsions contain a high proportion of oleic acid, a MUFA, that is generally considered to have a neutral effect on immune function $^{1,2}$. Most studies comparing soyabean oil-based emulsions with these newer emulsions have been performed using in vitro or ex vivo models. However, few studies have compared the effects of these emulsions on clinical outcomes. The need for clinical studies of olive oil-based emulsions has been highlighted ${ }^{2}$.

Considering that an olive oil-based emulsion with a high content of oleic acid could interfere less with immune function than a soyabean oil-based emulsion with a high content in linoleic acid, we compared the effects of these two emulsions 
on infection rate, appearance of new infection episodes, leucocyte count and leucocyte count evolution in critically ill patients receiving PN. Second, we compared the effect of these two emulsions on some acute-phase proteins and other health outcomes.

\section{Subjects and methods}

\section{Study design and patients}

This was an observational, retrospective, single-centre, twocohort study performed at Hospital del Mar, a 450-bed university hospital, in Barcelona, Spain. Patients included were adults ( $\geq 18$ years old), admitted to a general intensive care unit (ICU) who required PN for a minimum of $5 \mathrm{~d}$ during their ICU stay. Patients excluded were those on active treatment with immunosuppressive or antineoplastic drugs, or with several PN courses during their ICU stay. A pre-existing infection or being treated with antibiotics at the beginning of PN was not considered an exclusion criterion. The hospital ethical committee approved the study.

Patients were selected according to our ICU activity.

\section{Period of study}

Consecutive patients starting PN support from 20 May to 30 August 2002 were included in the first cohort (SOYA cohort) and consecutive patients starting PN support from 1 September to 31 December 2002 were included in the second cohort (OLIVE cohort). Patients in the SOYA cohort received a soyabean oil-based emulsion (Intralipid 20\%; Fresenius Kabi España, Barcelona, Spain) and patients in the OLIVE cohort received an olive oil-based emulsion (ClinOleic $20 \%$; Baxter, Valencia, Spain) as part of their PN. Composition of both emulsions is shown in Table 1 .

\section{Parenteral nutrition}

PN was administered as 'all-in-one' admixtures prepared daily following usual hospital practices. All admixtures were delivered through central catheters in a $24 \mathrm{~h}$ infusion. All patients received the same amino acid solution (Aminoplasmal L; Braun Medical, Rubi, Spain), and the same amounts of vitamins

Table 1. Composition of lipid emulsions used in the study

\begin{tabular}{lcc}
\hline & $\begin{array}{c}\text { Soyabean oil-based } \\
\text { emulsion }\end{array}$ & $\begin{array}{c}\text { Olive oil-based } \\
\text { emulsion }\end{array}$ \\
\hline Composition (g/100 ml): & 20 & 4 \\
Soyabean oil & - & 16 \\
Olive oil & $2 \cdot 20$ & $2 \cdot 25$ \\
Glycerol & $1 \cdot 20$ & 1.20 \\
Egg phospholipids & - & 0.03 \\
Sodium oleate & 11 & 12 \\
Fatty acid content $(\%)$ & 4 & 3 \\
Palmitic acid & 24 & 65 \\
Stearic acid & 53 & 17 \\
Oleic acid & 8 & 3 \\
Linoleic acid & 0.4 & 3.8 \\
$\alpha$-Linolenic acid & & \\
Oleic:linoleic ratio & &
\end{tabular}

(Cernevit; Baxter, Valencia, Spain) and trace elements (Addamel; Fresenius Kabi España, Barcelona, Spain).

The PN support was aimed to administer both a total energy load at least equal to that calculated by the Harris-Benedict equation for BMR and to a maximum of 1.5 times this value and at least $1 \mathrm{~g}$ protein $/ \mathrm{kg}$ per $\mathrm{d}(0.16 \mathrm{~g} \mathrm{~N} / \mathrm{kg}$ per $\mathrm{d})$. Lipid emulsions were administered from the first day of PN to provide an amount of $1 \mathrm{~g}$ fat $/ \mathrm{kg}$ per $\mathrm{d}$ when serum TAG levels were $<2 \mathrm{~g} / 1,0.75 \mathrm{~g} / \mathrm{kg}$ per $\mathrm{d}$ when serum TAG levels were between 2 and $3 \mathrm{~g} / \mathrm{l}$ or $0 \cdot 5 \mathrm{~g} / \mathrm{kg}$ per $\mathrm{d}$ when serum TAG levels were between $>3$ and $4 \mathrm{~g} / \mathrm{l}$. Lipid emulsion was withdrawn from PN when serum TAG levels reached $>4 \mathrm{~g} / \mathrm{l}$. During the anabolic phase, a maximum dose of $1.5 \mathrm{~g}$ fat $/ \mathrm{kg}$ per $\mathrm{d}$ could be administered if serum TAG levels remained $<2 \mathrm{~g} / \mathrm{l}$. Glucose was the only carbohydrate used. Doses were $3-5 \mathrm{~g} / \mathrm{kg}$ per $\mathrm{d}$ to provide between 60 and $70 \%$ of the PN non-protein energy supply. The amount of glucose was reduced and/or insulin dosage was increased in case of hyperglycaemia $(>11 \mathrm{~g} / \mathrm{l})$. Electrolytes $(\mathrm{Na}, \mathrm{K}, \mathrm{Mg}, \mathrm{Ca}$, phosphate and $\mathrm{Cl}$ ) were administered according to patients' needs.

Additionally, some patients received external energy sources concomitant to PN. These sources included: glucose as part of glucose solutions used to dilute and administer intravenous drugs; lipids as a vehicle in propofol emulsion, an intravenous sedative drug formulated in a $10 \%(\mathrm{w} / \mathrm{v})$ soyabean oil-based emulsion (Recofol 2\%; Schering España, Madrid, Spain); enteral nutrition in patients transitioning from PN to total enteral nutrition. Energy from these external sources was obtained from pharmacy records and taken into account when calculating the total amount of energy received by each patient.

\section{Biochemical and biological markers}

Patients were monitored on a regular basis for blood biochemical parameters including glycaemia, urea, creatinine, total bilirubin, alkaline phosphatase, alanine aminotransferase, $\gamma$-glutamyl transpeptidase, total proteins, albumin, fibrinogen, total cholesterol, serum TAG and $\mathrm{Hb}$. Erythrocyte and platelet counts were also monitored regularly. Blood $\mathrm{Na}, \mathrm{K}, \mathrm{Ca}, \mathrm{Mg}$ and phosphate were also monitored, but were not considered for the study.

\section{Infection and microbiological cultures}

Septic episodes were recorded and biological samples collected for microbiological culture. Septic episodes were considered when two or more of the following manifestations were present: body temperature $>38^{\circ} \mathrm{C}$ or $<36^{\circ} \mathrm{C}$, heart rate $>90$ beats/min, tachypnea with $>20$ breaths/min or hypoventilation with $\mathrm{PaCO}_{2}<32 \mathrm{mmHg}$, and abnormal leucocyte count $\left(>11 \times 10^{9}\right.$ cells/l or $<4 \times 10^{9}$ cells $\left./ 1\right)$.

Microbiological cultures were considered positive when one or more micro-organisms were isolated from biological samples obtained from a suspected focus of infection in patients who presented signs and symptoms of infection, and underwent antibiotic therapy to treat it. Microbiological cultures were considered negative when no micro-organisms were isolated from samples or when one or more micro-organisms were isolated from samples obtained from patients who did not present signs and symptoms of infection and were 
not treated with antibiotic agents. Bacteria studied were all aerobic and anaerobic gram-positive and gram-negative micro-organisms isolated in positive cultures. Fungi and yeast were also included when isolated. Samples for microbiological cultures were obtained from: the bloodstream; the respiratory tract by bronchoalveolar lavage or protected specimen brush; the urinary tract; wounds; catheters, skin and soft tissue; and other sources.

A patient with positive cultures was considered when he or she had at least one positive culture during his or her PN course. The number of positive cultures per patient was also recorded. Due to different lengths of PN courses, incidence rate was calculated as the number of positive microbiological cultures/patient per PN d. Infectious or septic episodes were treated according to pre-existing hospital-approved infectiontreatment protocols for ICU patients.

\section{Leucocyte monitoring}

Peripheral blood leucocyte counts were monitored daily. Peak leucocyte counts have been associated highly with infection ${ }^{13}$ and were used as an indicator of response to infection. Peak leucocyte count was studied in the period from day 5 after beginning PN support until the end of it. The first $5 \mathrm{~d}$ of PN were considered the period in which fatty acids from the PN oil emulsions were incorporated into leucocyte membranes. Three analyses were performed for this variable: a PN before-and-after comparison, a count-evolution comparison between cohorts, and peak comparisons between cohorts.

\section{Acute-phase proteins and inflammation markers}

As markers of response to inflammation, three plasma protein concentrations were recorded: albumin, fibrinogen and C-reactive protein.

\section{Other health outcomes}

Length of ICU and hospital stay and crude mortality rate were recorded.

\section{Sub-analysis of patients with and without pre-existing infection}

In an additional sub-analysis, patients with and without preexisting infection at the beginning of the PN course were analysed separately to assess the effect of this pre-existing condition in the results obtained.

\section{Statistical analysis}

Values for all blood parameters were considered valid when obtained during the PN course. Data are presented as mean values and standard deviations. Continuous variables were tested for normality using the one-sample KolmogorovSmirnov test. Parametric quantitative variables were studied using the independent-sample Student's $t$ test with the Levene's test for equality of variance or the paired-sample Student's $t$ test, when appropriate. Non-parametric quantitative variables were studied using the Mann-Whitney $U$ test. Measurements of the same variable were compared using repeated-measures ANOVA. Categorical variables were compared using the $\chi^{2}$ test and Fisher's exact test. Survival analysis was performed using Kaplan-Meier survival curves compared through the log-rank test. All tests were performed two-sided and statistical significance was considered when $P<0.05$. Statistical tests were carried out using SPSS for Windows, version 12.0 (SPSS Inc., Chicago, IL, USA).

\section{Results}

\section{Patients}

A total of forty-two patients received PN during their ICU stay; sixteen entered the SOYA cohort and twenty-three entered the OLIVE cohort during the study period. Three patients were excluded from the study: two received PN with the olive oil-based emulsion for less than $5 \mathrm{~d}$ and one received several PN courses with the soyabean oil-based emulsion.

Most patients were male ( $n$ 28; 72\%), non-obese (BMI 24.3 (SEM 0.52$) \mathrm{kg} / \mathrm{m}^{2}$ ), and with moderately severe illness (Mortality Prediction Model II score of -1.6415 (SEM $0 \cdot 1700)$ ). Mean age was approximately 60 years. The main reason for admittance was surgical intervention ( $n$ 24; $62 \%$ ). The mean calculated BMR was 5978 (SEM 148) kJ/ d. Patients were admitted to the ICU about $5 \mathrm{~d}$ before the beginning of the PN course. A high proportion of patients ( $n$ 30; 77\%) had required mechanical ventilation. Characteristics at the beginning of the PN course were not statistically different between groups and are shown in detail in Table 2. Main blood chemical analysis at the beginning of PN showed that patients had severe hypoalbuminaemia (albumin 23.5 (SEM 0.8) g/l), normal serum TAG levels (1.42 (SEM 0.13) $\mathrm{mmol} / \mathrm{l})$ and an acceptable renal function (calculated glomerular filtration rate 68.4 (SEM 5.9) $\mathrm{ml} / \mathrm{min}$ per $1.73 \mathrm{~m}^{2}$ ). Parameters such as creatinine, urea, alkaline phosphatase, total bilirubin, $\gamma$-glutamyl transpeptidase, total cholesterol, $\mathrm{Hb}$, erythrocyte counts and platelet counts were similar in both cohorts (data not shown). At the beginning of $\mathrm{PN}$, patients had a mild leucocytosis (12.16 $(\mathrm{SEM} 1.13) \times 10^{9}$ cells/l) and neutrophilia (10.75 (SEM $1.07) \times 10^{9}$ cells/l). Initial leucocyte counts are detailed in Table 2 .

\section{Parenteral nutrition}

All patients received similar energy and protein supplies, 1.22 (SEM 0.05) g protein/kg per d, 3.64 (SEM 0.14) g glucose/kg per d, and 0.88 (SEM 0.03) g lipid/kg per d, equivalent to a total energy intake of 118 (SEM 4) $\mathrm{kJ} / \mathrm{kg}$ per d, which corresponded to a total energy received:BMR ratio of 1.34 (SEM 0.03). Most patients ( $n$ 27; 69\%) received other external energy sources concomitant to PN (glucose solutions, propofol emulsion, enteral nutrition). These sources only represented 13 (SEM 3 ) $\mathrm{kJ} / \mathrm{kg}$ per d or $11 \%$ of the total energy received during the PN course. Patients in the OLIVE cohort received about 2.5-fold less linoleic acid and 2.5-fold more oleic acid than patients in the SOYA cohort. Nutritional intake in both cohorts is shown in Table 3. 
Table 2. Patients' characteristics at the beginning of parenteral nutrition

(Mean values with their standard errors)

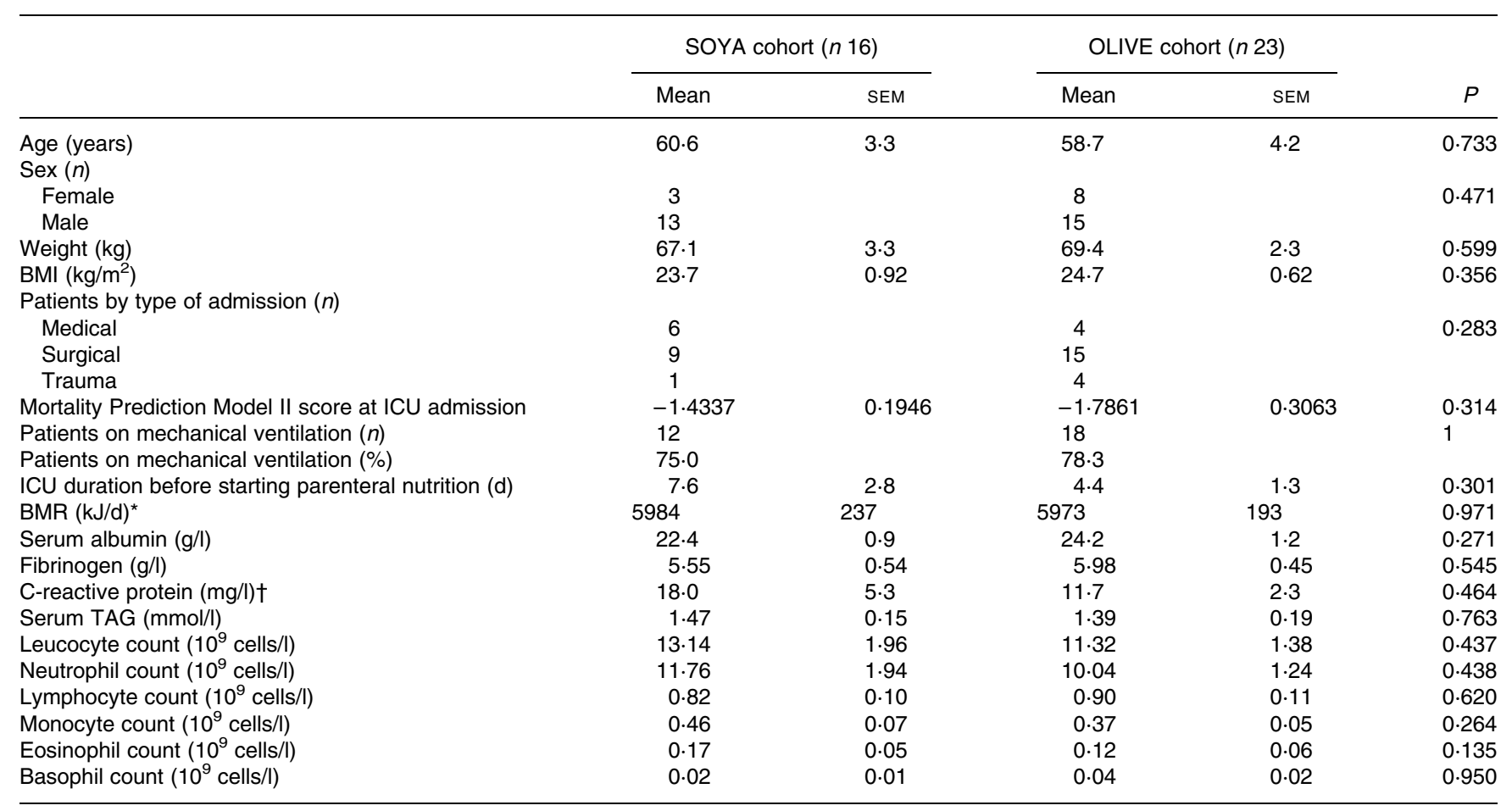

SOYA, soyabean oil-based emulsion; OLIVE, olive oil-based emulsion; ICU, intensive care unit.

${ }^{*}$ Harris-Benedict formula.

† Values of C-reactive protein were only available for five (31\%) patients in the SOYA cohort and eight (35\%) in the OLIVE cohort.

\section{Infection and microbiological cultures}

At the beginning of the PN course, nine (56\%) patients in the SOYA cohort and thirteen $(57 \%)$ in the OLIVE cohort presented infectious processes $(P=1)$. Characteristics of these infections are shown in Table 4.

Eighteen patients had at least one septic episode during the PN course; eight $(50 \%)$ in the SOYA cohort and ten $(43.5 \%)$ in the OLIVE cohort $(P=0 \cdot 688)$. Samples for microbiological cultures were obtained in thirty-seven patients $(95 \%)$. From these thirty-seven patients, thirty-two $(86 \%)$ had at least one positive culture; thirteen $(81 \%)$ in the SOYA group and nineteen $(83 \%)$ in the OLIVE group $(P=1)$. These positive cultures were considered as indicators of new infectious episodes. A first new episode appeared during the first $14 \mathrm{~d}$ of PN in all cases. A Kaplan-Meier curve with these data is depicted in Fig. 1. No differences between cohorts were detected $(P=0.936)$.

Patients classified by the origin of the cultured sample and the microbiological result (positive or negative) were not different between cohorts. Most cultures were from the bloodstream, catheter, skin and soft tissue, and respiratory tract samples. They were performed in fourteen (93\%), fourteen $(93 \%)$ and twelve $(80 \%)$ patients in the SOYA cohort and nineteen $(86 \%)$, sixteen $(73 \%)$ and seventeen $(77 \%)$ patients in the OLIVE cohort, respectively $(P=1.000 ; P=0.262$; $P=1.000)$. From them, positive cultures were present in seven $(50 \%)$, ten $(71 \%)$ and eight $(67 \%)$ patients in the SOYA cohort and eleven $(58 \%)$, eleven $(69 \%)$ and fourteen
(82\%) patients in the OLIVE cohort, respectively $(P=0.653$; $P=0.403 ; P=1.000)$. The rest of the patients classified by the origin of the cultured sample and the microbiological result were also not statistically different between cohorts.

The SOYA cohort had 6.6 (SEM 1.9) and the OLIVE cohort 6.2 (SEM 1.4$)$ positive cultures/patient $(P=0.857)$. When analysed by incidence rate, the groups did not differ. The SOYA group had 0.29 (SEM 0.05) positive cultures/patient per PN d and the OLIVE group had 0.30 (SEM 0.05) positive cultures/ patient per PN d $(P=0.922)$.

The isolated micro-organisms were distributed as follows: SOYA group, gram-negatives nine $(37.5 \%)$, gram-positives ten $(41.7 \%)$, anaerobes two $(7.4 \%)$ and yeasts three $(12.5 \%) v$. OLIVE group, gram-negatives thirteen $(34.2 \%)$, gram-positives thirteen $(34.2 \%)$, anaerobes three $(7.9 \%)$ and yeasts nine $(23.7 \%)(P=0.748)$.

\section{Leucocyte monitoring}

Patients were compared for leucocyte count before $v$. after the PN course. Mean initial and final leucocyte counts in the SOYA cohort were $13.14($ SEM 1.96$) \times 10^{9}$ cells $/ 1$ and 9.98 (SEM 1.09$) \times 10^{9}$ cells/l, respectively $(P=0 \cdot 222)$. Mean initial and final leucocyte counts in the OLIVE cohort were 11.32 $(\mathrm{SEM} 1.38) \times 10^{9}$ cells $/ 1$ and $15.83(\mathrm{SEM} 2.51) \times 10^{9}$ cells $/ 1$, respectively $(P=0.077)$. The leucocyte count evolution between cohorts resulted in no differences on days 5, 10, 12 and 18 of the PN course. These results are presented in Fig. 2. Leucocyte count decreased by $3.25($ SEM 2.48$) \times 10^{9}$ 
Table 3. Nutritional intake during the total parenteral nutrition course

(Mean values with their standard errors)

\begin{tabular}{|c|c|c|c|c|c|}
\hline & \multicolumn{2}{|c|}{ SOYA cohort ( $n$ 16) } & \multicolumn{2}{|c|}{ OLIVE cohort $(n 23)$} & \multirow[b]{2}{*}{$P$} \\
\hline & Mean & SEM & Mean & SEM & \\
\hline Parenteral nutrition duration (d) & $18 \cdot 7$ & 3.7 & $18 \cdot 7$ & 3.2 & 0.830 \\
\hline Total energy received $(\mathrm{kJ} / \mathrm{kg}$ per $\mathrm{d})$ & $118 \cdot 8$ & 7.5 & $117 \cdot 6$ & 3.8 & 0.875 \\
\hline $\begin{array}{l}\text { Total energy received:resting energy } \\
\text { expenditure ratio }\end{array}$ & 1.30 & 0.05 & 1.36 & 0.03 & 0.374 \\
\hline Protein intake $(\mathrm{g} / \mathrm{kg} \text { per } \mathrm{d})^{*}$ & 1.26 & $0 \cdot 10$ & 1.19 & 0.04 & 0.468 \\
\hline Glucose intake $(g / k g$ per $d) \dagger$ & 3.55 & 0.29 & 3.69 & 0.14 & 0.643 \\
\hline Lipid intake ( $\mathrm{g} / \mathrm{kg}$ per $\mathrm{d}) \ddagger$ & 0.91 & 0.04 & 0.86 & 0.04 & 0.365 \\
\hline \multicolumn{6}{|l|}{ Concomitant glucose solutions } \\
\hline Patients $(n)$ & 7 & & 9 & & 0.773 \\
\hline Patients (\%) & 44 & & 39 & & \\
\hline \multicolumn{6}{|l|}{ Concomitant propofol emulsion } \\
\hline Patients $(n)$ & 5 & & 12 & & 0.325 \\
\hline Patients (\%) & 31 & & 52 & & \\
\hline \multicolumn{6}{|l|}{ Concomitant enteral nutrition } \\
\hline Patients $(n)$ & 6 & & 8 & & 0.862 \\
\hline Patients (\%) & 38 & & 35 & & \\
\hline Concomitant enteral nutrition received (d) & 4.7 & $2 \cdot 1$ & 3.6 & 0.8 & 0.608 \\
\hline $\begin{array}{l}\text { Energy received by concomitant enteral nutrition } \\
\text { (kJ/kg per d of enteral nutrition) }\end{array}$ & 63 & 12 & 45 & 4 & 0.439 \\
\hline Linoleic acid received $(\mathrm{g} / \mathrm{d})$ & $29 \cdot 1$ & $1 \cdot 1$ & 11.8 & 0.9 & $<0.001$ \\
\hline Oleic acid received $(\mathrm{g} / \mathrm{d})$ & 12.5 & 0.6 & 33.4 & 1.6 & $<0.001$ \\
\hline Oleic acid:linoleic acid ratio received & 0.43 & 0.01 & 2.99 & 0.13 & $<0.001$ \\
\hline
\end{tabular}

SOYA, soyabean oil-based emulsion; OLIVE, olive oil-based emulsion.

${ }^{*}$ Considering protein from parenteral nutrition and additional protein intake in patients who received enteral nutrition.

† Considering glucose from total parenteral nutrition and additional glucose intake in patients who received enteral nutrition and/or intravenous glucose solutions.

$\ddagger$ Considering lipids from total parenteral nutrition and additional lipid intake in patients who received enteral nutrition and/or propofol emulsion.

cells/l in the SOYA cohort and increased by 4.51 (SEM $2.43) \times 10^{9}$ cells/ 1 in the OLIVE cohort $(P=0.036)$ from baseline to the end of the PN course. No differences were detected in the intermediate days (data not shown). When performing a repeated-measures ANOVA analysis on the leucocyte counts through time, leucocyte counts did not change considering as the within-subjects factor the day of the measure $(P=0 \cdot 124)$ or additionally considering as the between-subjects factor the type of emulsion administered $(P=0 \cdot 121)$.

The OLIVE cohort had a trend to a higher peak of leucocyte count when compared with the SOYA cohort, as shown in

Table 4. Pre-existing infections at the beginning of the total parenteral nutrition course

(Subjects and percentages)

\begin{tabular}{|c|c|c|c|c|c|}
\hline \multirow{2}{*}{$\begin{array}{l}\text { Patients with } \\
\text { pre-existing infection }\end{array}$} & \multicolumn{2}{|c|}{$\begin{array}{l}\text { SOYA } \\
\text { cohort } \\
(n 16)\end{array}$} & \multicolumn{2}{|c|}{$\begin{array}{l}\text { OLIVE } \\
\text { cohort } \\
\left(\begin{array}{l}n \\
23\end{array}\right)\end{array}$} & \multirow[b]{2}{*}{$P$} \\
\hline & $n$ & $\%$ & $n$ & $\%$ & \\
\hline $\begin{array}{l}\text { Peritonitis and abdominal } \\
\text { abscesses }\end{array}$ & 3 & 18.8 & 3 & $13 \cdot 0$ & 0.674 \\
\hline Pneumonia & 2 & $12 \cdot 5$ & 2 & 8.7 & 1 \\
\hline Septicaemia and septic shock & 1 & $6 \cdot 3$ & 4 & $17 \cdot 4$ & 0.631 \\
\hline Catheter-related infection & 1 & $6 \cdot 3$ & 1 & 4.3 & 1 \\
\hline Urinary tract infection & 1 & $6 \cdot 3$ & 0 & 0 & 0.410 \\
\hline Pulmonary tuberculosis & 1 & $6 \cdot 3$ & 1 & $4 \cdot 3$ & 1 \\
\hline Skin and soft tissue infections & 0 & 0 & 2 & 8.7 & 0.503 \\
\hline No infection & 7 & 43.8 & 10 & 43.5 & 1 \\
\hline
\end{tabular}

SOYA, soyabean oil-based emulsion; OLIVE, olive oil-based emulsion.
Table 5. This peak in the OLIVE cohort was $23 \%$ higher than in the SOYA cohort, but not at the expense of a certain leucocyte type.

\section{Acute-phase proteins and inflammation markers}

Initial albumin was not different between cohorts. Patients remained hypoalbuminaemic at the end of PN, but no differences were observed between cohorts (SOYA cohort 24.2 (SEM 1.6) g/l and OLIVE cohort 24.8 (SEM 1.3) g/l; $P=0.758$ ). Initial fibrinogen was comparable in both cohorts, but it showed a trend to higher levels in the OLIVE cohort at the end of PN (SOYA cohort 4.72 (SEM 0.29) g/l and OLIVE cohort 5.62 (SEM 0.36) $\mathrm{g} / \mathrm{l} ; P=0.078$ ). Values of C-reactive protein were only available for five $(31 \%)$ patients in the SOYA cohort and eight $(35 \%)$ in the OLIVE cohort. Initial values were not different in both cohorts. Values at the end of PN were 8.4 (SEM 0.8) $\mathrm{mg} / \mathrm{l}$ in the SOYA cohort and $11.0(\mathrm{SEM} 1.7) \mathrm{mg} / \mathrm{l}$ in the OLIVE cohort $(P=0.167)$ (Table 2).

No differences were detected in these three proteins when analysed from basal values to the end of PN within each cohort (data not shown).

\section{Other health outcomes}

Length of ICU and hospital stay and mortality rate were not statistically different between the groups. Patients remained in the ICU for 31.3 (SEM 6.4) $\mathrm{d}$ and at the hospital for 46.5 (SEM 6.3) $d$ in the SOYA cohort and 25.2 (SEM 3.4) and 45.4 


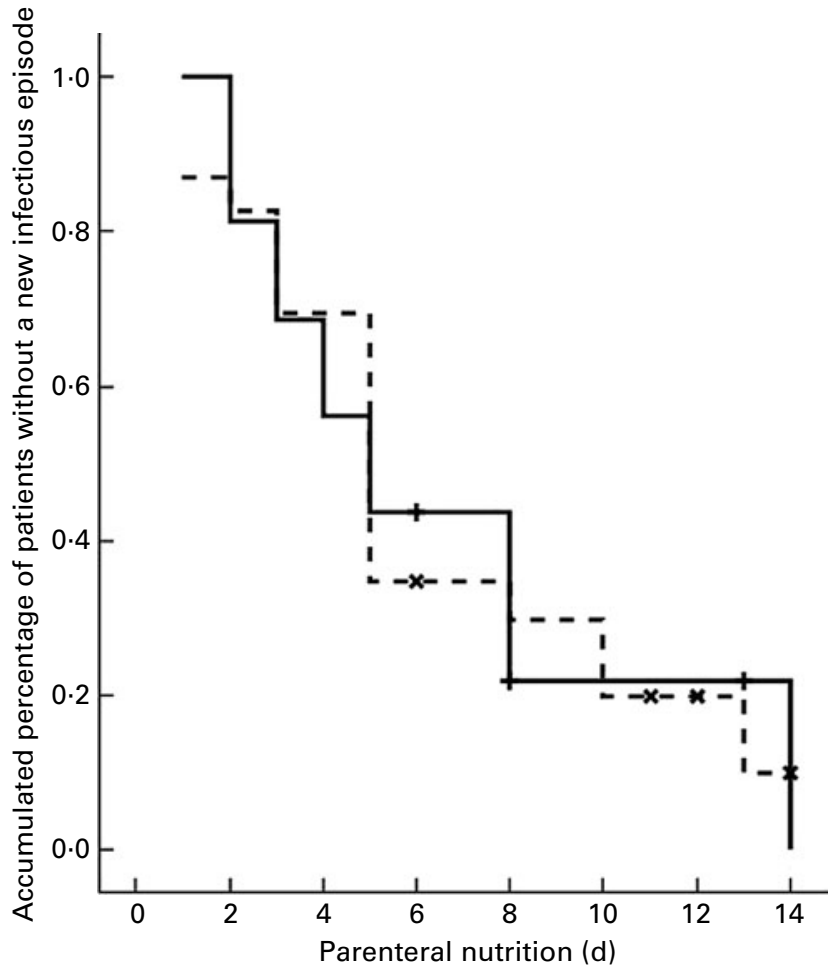

Fig. 1. Kaplan-Meier curve for a first new infectious episode during parenteral nutrition in soyabean oil-based emulsion (SOYA; ᄀ) and olive oil-based emulsion (OLIVE; - $)$ ) cohorts. The plots show the patients (\%) who remained free from new infectious episodes for each cohort during the first $14 \mathrm{~d}$ of parenteral nutrition. The difference between the cohorts was not significant $(P=0.936$; log-rank test). $(+)$, SOYA cohort censored; $(\mathbf{X})$, OLIVE cohort censored.

(SEM 4.9) d, respectively, in the OLIVE cohort $(P=0 \cdot 371$, $P=0.885$, respectively). Seven $(44 \%)$ patients died in the SOYA cohort and eleven $(47.8 \%)$ in the OLIVE cohort $(P=0.802)$.

\section{Sub-analysis of patients with and without pre-existing infection}

At the beginning of PN, twenty-two (56\%) patients had a preexisting infection, nine $(41 \%)$ of which received the soyabean oil-based emulsion and thirteen (59\%), the olive oil-based emulsion. Basal characteristics and energy intake from these patients did not differ from the general group (data not shown). Main results from the sub-analysis are presented in Table 6. Of interest, only final fibrinogen presented a trend to higher values in the OLIVE cohort. Seventeen (44\%) patients had no pre-existing infection; seven $(41 \%)$ in the SOYA cohort and ten $(59 \%)$ in the OLIVE cohort. As before, basal characteristics and energy intake were similar to those of the general group (data not shown). As shown in Table 6, groups presented no differences.

\section{Discussion}

The administration of an olive oil-based emulsion as part of PN has been demonstrated to be clinically safe and well tolerated ${ }^{1}$. This type of emulsion has been proposed to have less impact on the immune and inflammatory response ${ }^{1}$ and theoretically confers advantages in patients under PN for whom immune suppression may be deleterious, such as ICU patients $^{14,15}$. However, olive oil-based emulsions as part of PN had not been tested for their effects on infection in a clinical setting up to now. The present study is the first to compare the effects on infection of this emulsion with a soyabean oilbased emulsion in critically ill patients. Soyabean oil-based emulsions have been considered the standard for use in PN, despite being considered immune disturbing ${ }^{1}$.

In in vivo rodent models, olive oil-based emulsions have been shown greater lymphocyte activation ${ }^{16}$, greater bacterial clearance, preserved mononuclear leucocytes functions ${ }^{17}$, preserved leucocyte recruitment and emigration ${ }^{15}$ and better tissue regeneration ${ }^{18}$ when compared with soyabean

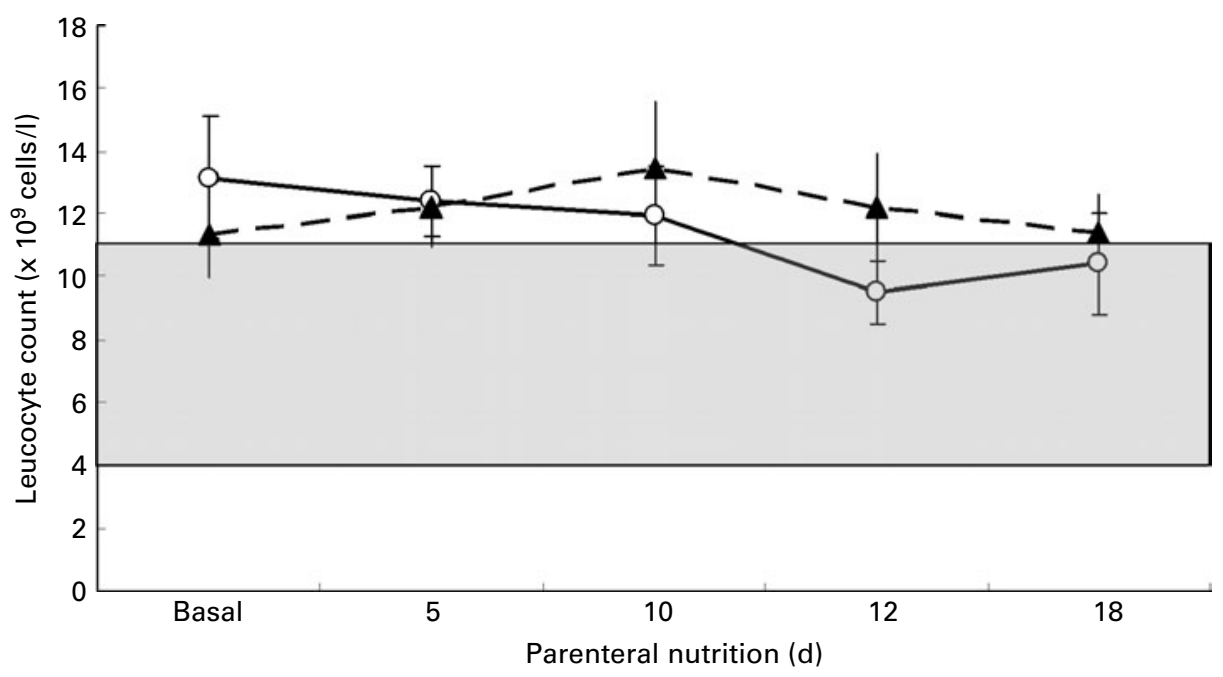

Fig. 2. Comparison of leucocyte counts between the soyabean oil-based emulsion (SOYA; -O-) cohort and the olive oil-based emulsion (OLIVE; - $\mathbf{\Delta - )}$ cohort during parenteral nutrition on days $0,5,10,12$ and 18 . Data are expressed as leucocyte concentration $\left(\times 10^{9}\right.$ cells/l). Values are means, with their standard errors represented by vertical bars. The difference between cohorts was not significant at any point. $(\square)$, Leucocyte concentration in the normal range $\left(4-11 \times 10^{9}\right.$ cells/l). 
Table 5. Peak leucocyte count from day 5 to the end of the total parenteral nutrition course (Mean values with their standard errors)

\begin{tabular}{|c|c|c|c|c|c|c|}
\hline \multirow[b]{3}{*}{ Cell type } & \multirow[b]{3}{*}{ NR $\left(10^{9}\right.$ cells $\left./ \mathrm{l}\right)$} & \multicolumn{4}{|c|}{ Counts $\left(10^{9}\right.$ cells/l) } & \multirow[b]{3}{*}{$P$} \\
\hline & & \multicolumn{2}{|c|}{ SOYA cohort ( $n$ 16) } & \multicolumn{2}{|c|}{ OLIVE cohort ( $n$ 23) } & \\
\hline & & Mean & SEM & Mean & SEM & \\
\hline Leucocyte & $4-11$ & $15 \cdot 28$ & $1 \cdot 21$ & $18 \cdot 86$ & 1.46 & 0.078 \\
\hline Neutrophil & $2 \cdot 5-8 \cdot 2$ & $13 \cdot 32$ & $1 \cdot 15$ & $16 \cdot 30$ & 1.43 & 0.128 \\
\hline Lymphocyte & $1 \cdot 5-5$ & 1.39 & 0.21 & 1.88 & 0.24 & 0.155 \\
\hline Monocyte & $0.2-1$ & 0.97 & 0.15 & $1 \cdot 10$ & 0.10 & 0.459 \\
\hline Eosinophil & $0.05-0.5$ & 0.42 & 0.07 & 0.53 & 0.08 & 0.338 \\
\hline Basophil & $0.01-0.15$ & 0.12 & 0.03 & 0.19 & 0.04 & 0.191 \\
\hline
\end{tabular}

SOYA, soyabean oil-based emulsion; OLIVE, olive oil-based emulsion; NR, normal range.

oil-based emulsions. In in vitro human immune cell models, olive oil-based emulsions have also been shown not to alter lymphocyte proliferation or IL-2 release ${ }^{19,20}$, to preserve neutrophil activation ${ }^{21,22}$ and functions ${ }^{15}$, and to induce low TNF- $\alpha$ and IL-1 $\beta$ inhibition in mononuclear leucocytes ${ }^{14}$ when compared with soyabean oil-based emulsions. Considering the results of these studies, a reduction in infection rate could theoretically be expected in patients who received olive oil-based emulsions compared with patients who received soyabean oil-based emulsions, since immune function would be better preserved. However, the present study could not detect any differences in infection rate or appearance of new infections in the studied cohorts. The advantages seen in vitro and in animal studies for olive oil-based emulsions were not transferred to better outcomes in the clinical setting. Many factors, other than the oil emulsion received, would affect patients' progress after injury, especially in critically ill patients.

Our leucocyte-count data showed that the OLIVE cohort had increased cell counts at the end of the PN course and had a trend to a higher peak when compared with the SOYA cohort. Unlike the present results for infections, the present results for leucocyte counts could be in agreement with previous in vitro studies. Soyabean oil-based emulsions promote lymphocyte and neutrophil death by apoptosis 8,15 and decrease leucocyte rolling flux, adhesion, and emigration ${ }^{15}$. These findings would explain the lower leucocyte counts in the SOYA cohort at the end of the PN course. Data are needed to know if soyabean oil-based emulsions have effects on leucocyte release from bone marrow in response to infection. This release is influenced by interleukins and $\mathrm{TNF}^{23}$, which, in turn, could be influenced by fatty acids.

The effects of olive oil-based emulsions have not been extensively studied. The present results on the acute-phase proteins serum albumin, fibrinogen and C-reactive protein are in agreement with previous published data. García-de-Lorenzo et al. $^{24}$, in a prospective, double-blind, randomised study, compared the tolerability and metabolic effects of PN containing an olive oil-based emulsion $v$. a long-chain- and mediumchain TAG emulsion in severely burned patients. They found no difference between groups in the serum levels of these acute-phase proteins at the end of the study. However, fibrinogen levels increased during the study in the patients who received the olive oil-based emulsion. In our OLIVE cohort, fibrinogen showed a trend to increased levels at the end of PN. We do not know the relevance of this finding. Fibrinogen is induced by IL- 6 and inhibited by TNF- $\alpha^{25}$. Olive oil-based emulsions did not change IL-6 production but diminished TNF- $\alpha$ in burned patients ${ }^{24}$, but they did not alter TNF- $\alpha$ in in vitro studies ${ }^{14,15}$.

Several other studies have focused on the heath outcomes or safety of olive oil-based emulsions in adults. Better outcomes have been obtained in a study in ICU patients. Huschak et al. ${ }^{26}$ compared high-fat (54.5\% of total energy intake) containing PN with olive oil-based emulsion $v$. high-glucose $(51 \%$ of total energy intake) containing PN with soyabean oil-based emulsion. Mean blood glucose levels were $1.3 \mathrm{mmol} / \mathrm{l}$ lower, and the duration of mechanical ventilation and length of

Table 6. Sub-analysis of patients with and without pre-existing infection (Mean values with their standard errors)

\begin{tabular}{|c|c|c|c|c|c|}
\hline & \multicolumn{2}{|c|}{ SOYA cohort } & \multicolumn{2}{|c|}{ OLIVE cohort } & \multirow[b]{2}{*}{$P$} \\
\hline & Mean & SEM & Mean & SEM & \\
\hline \multicolumn{6}{|c|}{ Patients with pre-existing infection at the beginning of PN } \\
\hline Peak leucocyte count $\left(10^{9}\right.$ cells $\left./ \mathrm{l}\right)$ & $15 \cdot 23$ & 1.69 & $18 \cdot 76$ & 1.84 & 0.145 \\
\hline Positive cultures (per patient per PN d) & 0.25 & 0.06 & 0.29 & 0.07 & 0.971 \\
\hline Final fibrinogen $(\mathrm{g} / \mathrm{l})$ & 4.56 & 0.33 & $5 \cdot 66$ & 0.40 & 0.076 \\
\hline \multicolumn{6}{|c|}{ Patients without pre-existing infection at the beginning of PN } \\
\hline Positive cultures (per patient per PN d) & 0.35 & 0.09 & 0.31 & 0.06 & 0.711 \\
\hline Final fibrinogen $(g / l)$ & 4.93 & 0.53 & 5.58 & 0.68 & 0.591 \\
\hline
\end{tabular}

SOYA, soyabean oil-based emulsion; OLIVE, olive oil-based emulsion; PN, parenteral nutrition. 
ICU stay were $7 \mathrm{~d}$ shorter in the high-lipid-containing $\mathrm{PN}$ group. Infectious complications were not directly studied, but the mean daily sepsis score was lower in the high-lipidcontaining PN group. Conclusions from this study are difficult to draw, since the authors compared two groups that did not receive the same energy load, glucose:lipid ratio, and fattyacid emulsion composition. The results could be influenced by lower blood glucose after a lower glucose load rather than a lipid emulsion effect. Other studies in patients under home $\mathrm{PN}^{27-29}$, under intradialytic $\mathrm{PN}^{30}$, or in paediatric patients ${ }^{31,32}$ with olive oil-based emulsions resulted in positive changes in lipid-related biochemical parameters, but not in clinical outcomes.

The present study had several limitations. First, it was designed as a retrospective study. Second, our patients were critically ill and not severely malnourished, and we do not know if the same results would have been observed in non-critically ill or severely malnourished patients. Third, we did not measure an extensive battery of inflammatory or immune markers. The present study was focused mainly on clinically relevant outcomes and markers rather than surrogate or experimental markers. Fourth, although abnormal leucocyte count is a widely used infection indicator in usual clinical practice, leucocyte count is also a variable parameter. Leucocytosis usually reflects the response of bone marrow to infectious and inflammatory processes ${ }^{31}$ and peak leucocyte count has been shown to be strongly related to microbial infection ${ }^{13}$. Finally, including more patients would have increased the statistical power. Our study sample size was able to detect a significant reduction in infection rate of $40 \%$ and a difference in peak leucocyte count of $5 \times 10^{9}$ cells $/ 1$ with standard power of 0.8 and type I error probability of 0.05 . In view of the present results, differences with clinical impact could have only been detected in a large trial.

In conclusion, the use of an olive oil-based emulsion in PN had no effect on infection, acute-phase proteins, major health outcomes, and presented higher leucocyte counts at the end of $\mathrm{PN}$ and a trend to higher peak leucocyte counts when compared with soyabean oil-based emulsion in ICU patients.

\section{Acknowledgements}

The authors have no conflict of interest concerning substances, drugs or procedures presented in this paper. No financial support has been received for the study.

\section{References}

1. Waizberg DL, Torrinhas RS \& Jacintho TM (2006) New parenteral lipid emulsions for clinical use. JPEN 30, 351-367.

2. Wanten G (2006) An update on parenteral lipids and immune function: only smoke, or is there any fire? Curr Opin Clin Nutr Metab Care 9, 79-83.

3. Heyland DK, MacDonald S, Keefe L \& Drover JW (1998) Total parenteral nutrition in the critically ill patient. JAMA 280, 2013-2019.

4. Heyland DK, Dhaliwal R, Drover JW, Gramlich L \& Dodek P (2003) Canadian clinical practice guidelines for nutrition support in mechanically ventilated, critically ill adult patients. JPEN 27, 355-373.
5. Anonymous (2002) Guidelines for the use of parenteral and enteral nutrition in adult and pediatric patients. American Society for Parenteral and Enteral Nutrition. JPEN 26, Suppl. 1, 1SA-138SA.

6. Mirtallo J, Canada T, Johnson D, Kumpf V, Petersen C, Sacks G, Seres D \& Guenter P; Task Force for the Revision of Safe Practices for Parenteral Nutrition (2004) Safe practices for parenteral nutrition. JPEN 28, S39-S70.

7. Waitzberg DL (2005) Evolution of parenteral lipid emulsions. Clin Nutr Suppl 1, Suppl. 3, 5-7.

8. Cury-Boaventura MF, Gorjao R, de Lima TM, Piva TM, Peres CM, Soriano FG \& Curi R (2006) Toxicity of a soybean oil emulsion on human lymphocytes and neutrophils. JPEN 30, $115-123$.

9. Waitzberg DL, Bellinati-Pires R, Salgado MM, Hypolito I, Colleto G, Yagi O, Yamamuro EM, Gama-Rodrigues J \& Pinotti HW (1997) Effect of total parenteral nutrition with different lipid emulsions on humans monocyte and neutrophil functions. Nutrition 13, 128-132.

10. Furukawa K, Yamamori H, Takagi K, Hayashi N, Suzuki R, Nakajima N \& Tashiro T (2002) Influences of soybean oil emulsion on stress response and cell-mediated immune function in moderately or severely stressed patients. Nutrition 18, 235-240.

11. Meyer K, Fegbeutel C, Hattar K, Sibelius U, Krämer HJ, Heuer KU, Temmesfeld-Wollbrück B, Gokorsch S, Grimminger F \& Seeger W (2003) Omega-3 vs. omega-6 lipid emulsions exert differential influence on neutrophils in septic shock patients: impact on plasma fatty acids and lipid mediator generation. Intensive Care Med 29, 1472-1481.

12. Grimble R (2005) Fatty acid profile of modern lipid emulsions: scientific considerations for creating the ideal composition. Clin Nutr Suppl 1, Suppl. 3, 9-15.

13. Bossink AWJ, Groeneveld ABJ, Hack CE \& Thijs L (1999) The clinical host response to microbial infection in medical patients with fever. Chest 116, 380-390.

14. Reimund JM, Scheer O, Muller CD, Pinna G, Duclos B \& Baumann $\mathrm{R}$ (2004) In vitro modulation of inflammatory cytokine production by three lipid emulsions with different fatty acid compositions. Clin Nutr 23, 1324-1332.

15. Buenestado A, Cortijo J, Sanz MJ, Naim-Abu-Nabah Y, Martinez-Losa M, Mata M, Issekutz AC, Marti-Bonmati E \& Morcillo EJ (2006) Olive oil-based lipid emulsion's neutral effects on neutrophil functions and leukocyte-endothelial cell interactions. JPEN 30, 286-296.

16. Moussa M, Le Boucher J, Garcia J, Tkaczuk J, Ragab J, Dutot G, Ohayon E, Ghisolfi J \& Thouvenot JP (2000) In vivo effects of olive oil-based lipid emulsion on lymphocyte activation in rats. Clin Nutr 19, 49-54.

17. Garnacho-Montero J, Ortiz-Leyba C, Garnacho-Montero MC, Garcia-Garmendia JL, Pérez-Paredes C, Moyano-Del Estad MR, Barrero-Almodóvar A \& Jiménez- Jiménez FJ (2002) Effects of three intravenous lipid emulsions on the survival and mononuclear phagocyte function of septic rats. Nutrition 18, $751-754$.

18. Ok E, Yilmaz Z, Karaküçük I, Akgün H \& Sahin H (2003) Use of olive oil based emulsions as an alternative to soybean oil based emulsions in total parenteral nutrition and their effects on liver regeneration following hepatic resection in rats. Ann Nutr Metabol 47, 221-227.

19. Granato D, Blum S, Rössle C, Le Boucher J, Malnoë A \& Dutot G (2000) Effects of parenteral lipid emulsions with different fatty acid composition on immune cell functions in vitro. JPEN 24, 113-118.

20. Versleijen M, Roelofs H, Preijers F, Roos D \& Wanten G (2005) Parenteral lipid modulate leukocyte phenotypes in whole blood, depending on their fatty acid composition. Clin Nutr 24, 822-829. 
21. Wanten G, Rops A, van Emst-de Vries SE, Naber $\mathrm{T}$ \& Willems P (2002) Prompt inhibition of fMLP-induced $\mathrm{Ca}^{2+}$ mobilization by parenteral lipid emulsions in human neutrophils. J Lipid Res 43, 550-556.

22. Wanten G, Kusters A, van Emst-de Vries SE, Tool A, Roos D, Naber T \& Willems P (2004) Lipid effects on neutrophil calcium signaling induced by opsonized particles: platelet activating factor is only part of the story. Clin Nutr 23, $623-630$

23. Abramson N \& Melton B (2000) Leukocytosis: basics of clinical assessment. Am Fam Physician 62, 2053-2060.

24. García-de-Lorenzo A, Denia R, Atlan P, Martinez-Ratero S, Le Brun A, Evard D \& Bereziat G (2005) Parenteral nutrition providing a restricted amount of linoleic acid in severely burned patients: a randomised double-blind study of an olive oil-based lipid emulsion $v$. medium/long-chain triacylglycerols. Br J Nutr 94, 221-230.

25. Gabay C \& Kushner I (1999) Acute-phase proteins and other systemic responses to inflammation. $N$ Engl J Med 340, 448-454.

26. Huschak G, zur Nieden K, Hoell T, Riemann D, Mast H \& Stuttmann R (2005) Olive oil based nutrition in multiple trauma patients: a pilot study. Intensive Care Med 31, 1202-1208.

27. Thomas-Gibson S, Jawhari A, Atlan P, Le Brun A, Farthing M \& Forbes A (2004) Safe and efficacious prolonged use of an olive oil-based lipid emulsion (Clinoleic $\mathbb{C}$ ) in chronic intestinal failure. Clin Nutr 23, 697-703.

28. Reimund JM, Rahmi G, Escalin G, Pinna G, Finck G, Muller CD, Duclos B \& Baumann R (2005) Efficacy and safety of an olive oil-based intravenous fat emulsion in adult patients on home parenteral nutrition. Aliment Pharmacol Ther 21, 445-454.

29. Vahedi K, Atlan P, Joly F, Le Brun A, Evard D, Perennec V, RouxHaguenau D, Bereziat G \& Messing B (2005) A 3-month doubleblind randomised study comparing an olive oil with a soyabean oil-based intravenous lipid emulsion in home parenteral nutrition patients. Br J Nutr 94, 909-916.

30. Cano NJM, Saingra Y, Dupuy AM, et al. (2006) Intradialytic parenteral nutrition: comparison of olive oil versus soybean oil-based lipid emulsions. Br J Nutr 95, 152-159.

31. Goulet O, de Potter S, Antébi H, et al. (1999) Long-term efficacy and safety of a new olive oil-based intravenous fat emulsion in pediatric patients: a double-blind randomized study. Am J Clin Nutr 70, 338-345.

32. Göbel Y, Koletzko B, Böhles HJ, Engelsberger I, Forget D, Le Brun A, Peters J \& Zimmermann A (2003) Parenteral fat emulsions based on olive and soybean oils: a randomized clinical trial in preterm infants. J Pediatr Gastroenterol Nutr 37, $161-167$. 